\title{
PIBID E O MUNDO DO TRABALHO: UMA EXPERIÊNCIA DE RETEXTUALIZAÇÃO E ADAPTAÇÃO TEATRAL EM SALA DE AULA
}

\author{
Cláudia T. Alves ${ }^{1}$
}

Durante o ano de 2015, o projeto "O mundo do trabalho", do PIBID Letras - Unicamp, foi desenvolvido em diversas escolas da rede pública da região metropolitana de Campinas. $\mathrm{O}$ presente artigo irá relatar as atividades realizadas na EMEB Franco Montoro ${ }^{3}$, localizada no município de Valinhos, com duas turmas de $8^{\circ}$ ano do ensino fundamental, bem como os resultados alcançados e as experiências vivenciadas a partir da realização desse projeto de iniciação à docência.

Inicialmente, é importante destacar que a temática referente ao projeto desenvolvido foi escolhida para que pudessem ser realizadas atividades a partir da realidade dos alunos de ensino fundamental - isto é, a realidade de que em poucos anos eles deveriam pensar a transição entre o ensino básico e a escolha de uma profissão. Nesse sentido, gostaríamos de esclarecer que o conceito de mundo do trabalho utilizado na elaboração do projeto pretende expandir a ideia de mercado de trabalho, a fim de que os alunos pudessem ser apresentados a novas possibilidades e a desdobramentos diversos referentes ao conceito de trabalho.

Sendo assim, propusemos que houvesse a retextualização de capítulos selecionados do romance Pode me beijar se quiser (2010), de Ivan Ângelo, e a posterior encenação teatral do roteiro escrito pelos próprios alunos. Pensando na relação dessas atividades com o mundo do trabalho, partimos do pressuposto de que seria interessante que os alunos conhecessem o universo das encenações teatrais, o qual perpassa desde a função dos roteiristas até os atores e os profissionais da montagem da peça, como contrarregras e cenógrafos.

Para organizar os procedimentos de retextualização e adaptação teatral, usamos as definições e as esquematizações propostas por Dell'Isola (2007) como base para nosso planejamento. Dividimos o processo de retextualização nas seguintes etapas:

Leitura dos textos - leitura dos capítulos selecionados de Pode me beijar se quiser;

Compreensão textual - observação e levantamento das características de textualização do texto lido;

Identificação do gênero - com base na leitura, compreensão e observação das características do gênero narrativo;

Retextualização - escrita de um novo texto, orientada pela transformação do gênero narrativo em roteiro teatral;

Conferência - verificação do atendimento às condições de produção: o gênero textual escrito, a partir do original, deve manter, ainda que em parte, o conteúdo do texto lido;

Identificação - identificar, no novo texto, as características do gênero-produto da retextualização;

Reescrita - trata-se da escrita da versão final do texto, feitos os ajustes necessários.

\footnotetext{
${ }^{1}$ Universidade Estadual de Campinas.

${ }^{2}$ Este artigo se refere à experiência de uma das equipes do PIBID (Programa Institucional de Bolsas de Iniciação à Docência) da Licenciatura em Letras do IEL (Instituto de Estudos da Linguagem) - UNICAMP (Universidade Estadual de Campinas), sob a coordenação da Profa. Dra. Anna Christina Bentes. O projeto PIBID Letras UNICAMP (2014), "Diversidade Linguístico-Cultural, Práticas Escolares e Formação Inicial em Letras", é coordenado pelas professoras Anna Christina Bentes, Márcia Mendonça e Marcos Lopes, atuando em 06 escolas da região metropolitana de Campinas.

${ }^{3}$ O PIBID na EMEB Franco Montoro aconteceu sob supervisão do Prof. Alvim José de Paula Neto, com a colaboração da Profa. Ana Elisa Novaes Vidal Martins.
} 
Quanto à adaptação teatral, optamos por dividir as turmas em grupos menores que ficassem responsáveis pelas tarefas referentes à montagem da peça. As turmas se organizaram, então, entre aqueles que iriam: atuar, dirigir, elaborar o cenário, realizar a sonoplastia, selecionar o figurino, preparar a maquiagem, e fazer os registros audiovisuais dos ensaios e da apresentação final.

Para o cumprimento de todas essas etapas, foi pensado um cronograma de aproximadamente 10 semanas, sendo duas aulas por semana em cada turma. $\mathrm{O}$ calendário proposto foi suficiente para que pudéssemos concluir todas as atividades planejadas adequadamente. Após a apresentação final das peças, retornamos à escola mais uma vez para gravar os depoimentos dos alunos sobre a realização do projeto e sobre suas impressões quanto à encenação da peça que eles produziram.

Em linhas gerais, o projeto apresentou resultados bastante satisfatórios. Todo esse processo de desenvolvimento resultou em um roteiro de teatro e uma peça teatral a cada turma participante do projeto. Além desses resultados, foi possível notar uma série de avanços ocorridos em relação à formação dos alunos na escola, bem como dos licenciandos.

Em relação aos roteiros, pudemos observar textos criativos, que souberam adaptar a narrativa ao contexto de encenação. Já em relação às encenações, presenciamos a montagem empolgada de peças que envolverem e motivaram os alunos a se envolver com as atividades escolares. Além disso, durante todo o processo de desenvolvimento desses materiais, pudemos observar uma série de resultados interessantes, que corroboraram a importância desse tipo de atividade direcionada a alunos do Ensino Fundamental. Desde as primeiras etapas, referentes sobretudo à retextualização, as turmas se destacaram pelo desenvolvimento de certas habilidades de leitura e escrita. Foi possível notar o desenvolvimento dos alunos referente a:

interpretação de textos narrativos, reconhecendo os elementos que os compõem (personagens, tempo, espaço, narrador);

processo de escrita de um roteiro teatral, observando como os elementos narrativos são alterados na retextualização;

adaptação da linguagem escrita para a linguagem oral.

A participação dos alunos na construção do roteiro contribuiu também para aprimorar a confiança deles em sua capacidade de expressão verbal e análise de texto, pois partilharam suas opiniões junto aos colegas para a construção de uma peça que fosse escrita por todos. Também o estímulo do trabalho em grupo, sem a necessidade de cobranças exaustivas de nossa parte, foi ganhando espaço gradativamente e pode ser percebido quando, ao fim da preparação da peça, já era possível ver que eles se mobilizaram por si sós para que o trabalho ficasse adequado. Nesse sentido, os alunos puderam aprender a ser mais autônomos e a se autogerirem como grupo.

Também nesse sentido, e levando em consideração a montagem da peça de teatro, houve o aprimoramento da expressão oral dos alunos, melhorando suas capacidades de falar em público - sobretudo em relação aos alunos mais tímidos, que levaram mais tempo para se envolver com o projeto -, e suas aptidões para atuar, assumindo personagens e realizando adequações orais e corporais necessários para interpretá-los.

Finalmente, foi possível observar a importância de um trabalho desenvolvido em grupo. Os alunos assumiram noções de compromisso e respeito, desenvolvendo a percepção da responsabilidade de cada um diante de um trabalho coletivo, que envolvesse todos. Destacamos o empenho de todos na organização e na divisão de tarefas, principalmente das funções que envolviam trabalhos manuais, como a construção de cenários e preparação de figurinos.

A experiência de retextualização e de adaptação teatral proporcionada pelo PIBID foi, sem dúvidas, um momento de descoberta das capacidades desses alunos. Eles construíram, dia 
após dia, a criação que apresentaram. Para tanto, assumiram responsabilidades e souberam se envolver com cada detalhe da organização do que estavam construindo. $\mathrm{O}$ mundo do trabalho se revelou como um experimento prazeroso, que para além das obrigações do universo adulto, pode ser entendido como uma atividade de engrandecimento e aprendizagem.

Ademais, do ponto de vista dos licenciandos, o projeto possibilitou uma experiência inigualável de prática docente, sobretudo por propiciar nossa atuação efetiva como educadores na escola. Graças às atividades propostas através do PIBID, pudemos entrar em contato com o universo de uma sala de aula e nos envolver com as mais variadas etapas da preparação de um projeto escolar, isto é, desde o planejamento e a preparação das aulas referentes ao desenvolvimento da retextualização e da adaptação teatral, bem como o acompanhamento e a avaliação continuada dos exercícios realizados. Por fim, foi muito significativo para todos os licenciandos envolvidos vivenciar esse momento de iniciação à convivência com alunos de diversas origens e com diferentes histórias pessoais, partindo da ideia que essa é uma realidade a todos que se dedicam a ser professores. Em suma, o projeto nos proporcionou uma bagagem de ensino, pois nos sentimos realmente parte integrante das salas de aula em que estivemos presentes e responsáveis pelo desenvolvimento das atividades propostas, mas, ao mesmo tempo, vivenciamos uma experiência de aprendizagem extraordinária, afinal o PIBID permitiu que tivéssemos nossas primeiras experiências como orientadores de uma rede de conhecimento estabelecida entre alunos e futuros professores.

\section{Referências}

ÂNGELO, I. Pode me beijar se quiser. São Paulo: Ática Editora, 2010.

CONCEIÇÃO, J. V. O ensino de gêneros orais públicos: o que o teatro tem a ver com isso? 2011. Monografia de Letras. Instituto de Letras, Universidade Federal do Rio Grande do Sul, Porto Alegre. 2011.

BOUZADA, C. P.; FARIA, M. D. A.; SILVA, A. A retextualização como recurso didático para a produção textual. The ESPecialist, v. 34, n. 1, p. 45-68, 2013. Disponível em: <http://revistas.pucsp.br/index.php/esp/article/viewFile/13174/14307>. Acesso em: 05/06/2016.

DELL'ISOLA, R. L. P. Retextualização de gêneros escritos. Rio de Janeiro: Lucerna, 2007.

FERREIRA, M. R. D. S. Retextualização em sala de aula: Uma experiência de criação de Roteiro a partir da leitura de contos. UFMG, 2012. Disponível em: <https://www.ufmg.br/proex/ddc/ufmgjovem2012/docs/mcped/14-criacao_de_roteiro.pdf $>$. Acesso em: 05/06/2016.

MATE, A. Uma proposta de adaptação de textos literários para a linguagem teatral: "Tudo certo como dois e dois são cinco". São Paulo: Cultura Acadêmica Editora, 2012. Disponível em: <http://acervodigital.unesp.br/bitstream/123456789/40522/1/01d18t07.pdf > . Acesso em: 05/06/2016. 
PIBID E O MUNDO DO TRABALHO: UMA EXPERIÊNCIA DE RETEXTUALIZAÇÃO E ADAPTAÇÃO...

\section{Sobre a autora}

Cláudia T. Alves é aluna de Licenciatura em Letras no Instituto de Estudos da Linguagem da Unicamp. Ingressou no projeto "Diversidade Linguístico-Cultural, Práticas Escolares e Formação Inicial em Letras", desenvolvido no âmbito do PIBID, em 2015.

E-mail: clautalves@gmail.com. 